\section{A brand new single tuft brush}

With more than 235 years' success with proven oral health solutions, don't miss Wisdom Toothbrushes at BDIA Dental Showcase this October.

New for this year is the Wisdom Super Slim Interspace brush that features an extra-soft, longer, thinner tuft, ideal for cleaning deeper into periodontal pockets. The single tuft design is also suited to cleaning around crowns, bridgework and orthodontic appliances.

Another highlight of the extensive portfolio is sure to be the Wisdom Clean Between Interdental Brushes. Clinically proven to help reduce gingival disease, these unique flexible brushes feature a tapered design, super-soft rubber coating and micro-fine rubber filaments for a gentle yet highly effective clean.

\section{Just like paper, stone or scissors}

Just like playing paper, stone or scissors, when a clinician decides which type of material (amalgam, composite or GIC) to use to restore stress-bearing areas in cavitated posterior teeth, they use their specialised knowledge and expertise to decide which one is most appropriate for each patient and themselves.

If they decide that a GIC would be the most appropriate solution for the Class I or II restoration, then GC's EQUIA Forte bulk fill glass hybrid restorative is the obvious answer because of its enhanced physical
The three sizes available slide easily into any space, and being wire-free, they are ideal for patients who find wire interdental brushes difficult or uncomfortable to use.

Also, discover the Dentist Dispenser Pack, which contains sample sachets of Wisdom Clean Between Interdental Brushes for trial on patients.

In addition, the team will dem-

onstrate the Wisdom Clean Between Easy Slide Y Shaped Floss Harps with PTFE tape, Wisdom Easy Flosser also with PTFE tape and the popular Wisdom Interproximal Brush, with various samples available.

Find out more at the BDIA Dental

Showcase - stand O12.

www.wisdomtoothbrushes.com

\section{Performance, value and peace of mind}

If you're looking for top quality decontamination equipment with outstanding service and value, don't miss Eschmann at BDIA Dental Showcase.

Having driven standards in infection control for the last 50 years with the Little Sister range of autoclaves, Eschmann offers an array of solutions designed to deliver maximum performance, durability and functionality.

What's more, all products including the Little Sister SES 2010 and Little Sister SES 3000B autoclaves come with free installation,

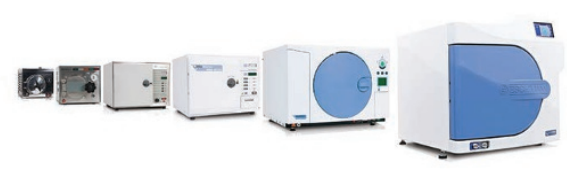

CPD training for staff, annual validation and a Lifetime Breakdown Warranty as standard.

Providing all the ongoing support and ultimate peace of mind you need, Eschmann's dedicated, fully qualified engineers already care for half of all dental practices in the UK.

For more information on these services and products, as well as the latest Meile PG8581 washer disinfector, visit Eschmann on stand G54 at BDIA Dental Showcase.

For more information on the highly effective and affordable range of decontamination equipment and products from Eschmann, visit www.eschmann.co.uk or call 01903753322.

\title{
A passion for excellent and beautiful dentistry
}

Do you strive to practise excellent dentistry? Then you would do well to visit the British Academy of Cosmetic Dentistry's (BACD) stand at this year's BDIA Dental Showcase.

Members of the BACD will be on stand throughout the event to tell delegates just what the BACD stands for - and how they can get involved themselves.

United by a passion for excellent and beautiful dentistry, the Academy is comprised of professionals who pride themselves on delivering exemplary

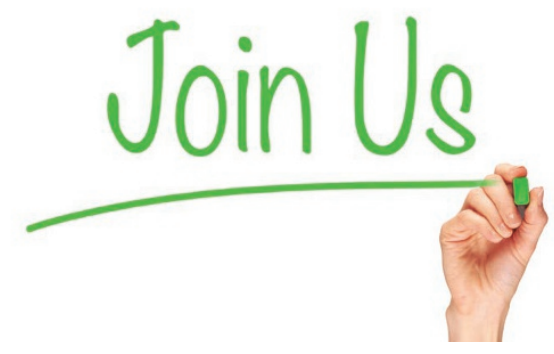

education, unmissable conferences and events, and unprecedented support to those dentists who aspire to perfection every day.

Delegates to the stand this year will be in time to learn more about the BACD's flagship event in November, the BACD Annual Conference which, this year, will be focussed on 'The Digital Revolution' - and the host of world-class speakers that are scheduled to present across the inspirational three-day event.

This is just one of the benefits of BACD membership which will be showcased on the Academy's stand at BDIA Dental Showcase this year - be sure to visit in order to learn about the many others on offer!

For further enquiries about the British Academy of Cosmetic Dentistry visit www. bacd.com. 